\title{
Main Variables of Brazilian Public Policies on Biomass use and Energy
}

\author{
Izabel Biernaski ${ }^{*}$, Christian Luiz Silva ${ }^{1}$ \\ ${ }^{1}$ Universidade Tecnológica Federal do Paraná, Curitiba, Brazil.
}

\begin{abstract}
Biomass is an important energy source, since it considers wastes discarded by other productive processes as inputs. As such, the determination of the most relevant variables, within an institutional dimension, exerts a significant influence to point out actions that should receive greater attention for the satisfactory implementation and monitoring of national public policies. Therefore, the general objective of this study is to determine, within the institutional dimension of the State, the most relevant variables for the decision making of public policies that consider the biomass source as an alternative to the energy matrix of the Brazilian territory. In order to reach the proposed objective, the method used for this research is qualitative and descriptive, using content analysis and the establishment of indexes for the determination of the variables. As a result, 12 most relevant variables have been considered, following the criterion of greater direct and / or indirect frequency, in the formation of these public policies considering the reuse of waste and energy generation: 1) greenhouse effect, 2) contamination, 3) waste disposal, 4) inputs, 5) technology, 6) biofuel, 7) biogas, 8) electric power, 9) society, 10) composting, 11) costs, and 12) investments.
\end{abstract}

Keywords: Public policies and biomass, Biomass and energy, Public policies and circular economy.

*Author of correspondence: izabel.biernaski@gmail.com 


\section{INTRODUCTION}

Energy is one of the most important tools for individuals to perform their activities effectively and satisfactorily. The first source of energy of human beings was biomass, stemming from the burning of the wood to make fire [8] However, in the last century, biomass began to be less used worldwide due to the growth in the continued use of nonrenewable energy sources such as petroleum, coal and natural gas. One again, this situation has undergone changes, since most countries, motivated by the harmful effects of these sources and the energy dependency, are looking for renewable alternatives in the constitution of their energetic matrices [3]. One of the main impacts generated by this source is in the process of converting biomass into energy, which can release particulate emissions that are harmful to the environment and society. However, combined with energetic and technological efficiency, it represents a source of energy with low environmental impact and if explored in a rational way, its effect can be practically nullified, when biomass grows again in the productive system.[2].

The reuse of waste, considered as biomass, has been widely used as an alternative and sustainable source for the generation of numerous energy sources. In this scenario, more and more resource processing technologies gain the attention of the agents of this process, since they make a new option for the reuse, recycling and recovery of resources [1]. This consideration is in line with the proposal of a circular economy, contrary to the current linear model of economy (extract-produce-dispose), which increasingly generates negative impacts worldwide and jeopardizes the sustainability of the planet and the productive system [9].

The State is considered one of the main agents of this process because, through the construction of conceptual bases, techniques and institutionalization, in each instance and at each territorial scale, it enables possibilities and conditions for the articulation of public policies [6]. These public policies, in turn, are capable of jointly focusing on the reuse of waste in the generation of energy as an alternative and sustainable action throughout the territory and for the benefit of society.

Therefore, this study seeks to highlight the main actions taken in Brazil through its public policies in the reutilization of resources and energy generation, considering biomass as the protagonist in this issue, as the waste discarded by other productive processes can be considered as inputs, to be used again by society. Thus, the determination of the most relevant variables, within an institutional dimension, exerts an essential influence to indicate the actions that should receive greater attention for the satisfactory implementation and monitoring of national public policies in Brazil. In view of the above, the general objective of this study is to determine within the institutional dimension of the State, the most relevant variables for the decision making of public policies, that consider the energy source biomass as an alternative to the energy matrix of the Brazilian territory.

\section{MATERIAL AND METHODS}

In order to reach the proposed objective, the method used for this study is predominantly qualitative and descriptive, mainly using content analysis, which consists of three stages: pre-analysis, coding of the material and treatment of the results obtained [5]. Firstly, a bibliographical and documentary survey of official websites is carried out regarding the approach and creation of public policies that involve, directly or indirectly, the reuse of resources and the generation of renewable energies, in response to the principles of the circular economy. As a result of this phase, a score chart was 
drawn up based on the intensity of the presence of the following key words considered in these documents: reuse, generation of energy, waste and biomass.

These keywords are then searched in the main direct national public policies that address environmental issues, and thus, intensity indexes are assigned in the relationship of these public policies with the source of biomass and energy generation. Firstly, the intensity of the presence of each keyword was measured, through the qualitative analysis of these public policies, in terms of presence: value 0 for the absence of the keyword; or value 2 for the partial presence of the keyword or synonym; or value 3 for the full presence of the key word or synonym.

Based on this evaluation of the presence of the keywords, a grouping of four categories (four keywords searched) was performed according to the relation of their synonyms to each other to facilitate the understanding of the analysis. For the formulation of the index, the arithmetic average between the values attributed to the presence of the keywords of which each public policy is related was used, following the criterion of the levels of frequency that are addressed in these public policies.

Following this, a clipping of the public policies that obtained indicators with greater correlation with biomass (above 0,5 ) is carried out and, thus the variables that are more present in these public policies following the same criterion used for the survey of public policies are determined: considering the frequency of the presence of keywords and synonyms in these public policies.

This criterion deserves to be highlighted, since for some research it is not usually recommended. However, the proposal of this research, it is considered valuable because it indicates the theme that is most frequent in the public policies, becoming an influential variable in the institutional scope. Finally, an analysis of the results and implications is carried out, considering these variables for the elaboration of public policies and their impact on the sustainability of the Brazilian energy matrix.

\section{RESULTS AND DISCUSSION}

The results presented allow us to determine the main variables of public policies present in a transcendental way in the spheres of biomass use in the composition of the Brazilian energy matrix. The main public policies that directly address the issue of waste and energy in its structure are listed in Table 1, as well as the obtained indicators for the relation with the incentive to use biomass as an energy source:

Table 1 - Index of the main Brazilian public policies concerning biomass

\begin{tabular}{llll}
\hline Year & Public Policy & Law Number & Index \\
\hline 1981 & National Environmental Policy & Law 6.938 & 0,55 \\
\hline 1997 & National Energy Policy & Law 9.478 & 0,9 \\
\hline 1999 & National Policy on Environmental Education & Law 9.795 & 0,2 \\
\hline 2007 & National Policy on Basic Sanitation & Law 11.445 & 0,8 \\
\hline 2009 & National Policy on Climate Change & Law 12.187 & 0,65 \\
\hline 2010 & National Policy on Solid Waste & Law 12.305 & 0,9 \\
\hline
\end{tabular}

Source: the authors

From these results, it is possible to consider that the following national public policies are the basis for the determination of the most relevant variables for institutional decision-making that consider biomass as an alternative for the energy matrix in Brazil: National Solid Waste Policy (Law 12,305 of 2010), National Policy on Climate Change (Law 12,187 of 2009), National Policy on Basic Sanitation (Law 11,445 of 2007), 
National Energy Policy (Law 9,478 of 1997) and National Environmental Policy (Law 6.938 of 1981).

Based on these public policies, twelve more influential variables were considered, following the criterion of greater direct and / or indirect frequency, in the constitution of these public policies before the reuse of waste and energy generation: 1) greenhouse effect, 2) contamination, 3) waste disposal, 4) inputs, 5) technology, 6) biofuel, 7) biogas, 8) electricity, 9) society, 10) composting, 11) costs and 12) investments as shown in Figure 1.

It can be seen that, of the twelve variables, the ones that stand out most in the whole scenario along the six national public policies analyzed, are: Biogas, Greenhouse Effect, Waste Allocation and Investments. Moreover, it is possible to perceive that each variable has a greater intensity in a certain policy that addresses it, for example, Waste Disposal in the National Solid Waste Policy.

Such a contact is necessary so that the analysis of these variables is weighted by the bias in which they are more frequent in the approach of the Brazilian legislation, sometimes in a determined public policy, or less frequent in another public policy. For this reason, in this study, the extent of twelve variables was considered, aiming at a greater understanding of the analysis, given the selection of the twelve national policies most present in a transcendental way in the spheres of the use of biomass in the constitution of the Brazilian energy matrix.

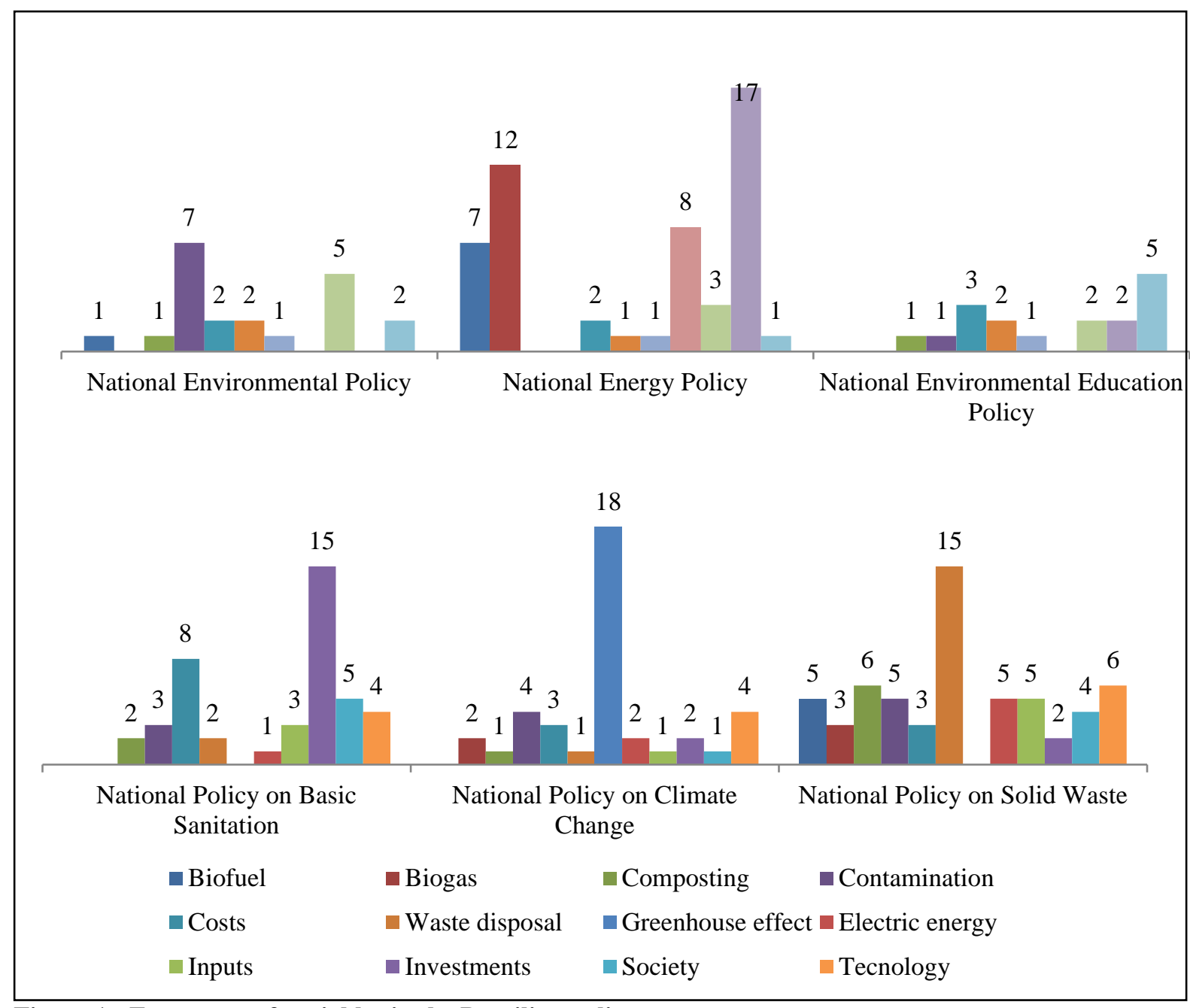

Figure 1 - Frequency of variables in the Brazilian polices

Source: the authors 
The issue of energy is increasingly becoming notorious in the elaboration of public policies worldwide. It is in this context that the use of renewable energies is emerging, especially for the use of biomass as an energy source combined with the circular economy, since it has a dual objective: to eliminate waste and increase energy production, given that biomass sources are abundant [1], [7].

One of the main factors in the high production of consumer goods and population growth is the direct impact on the growing generation of solid waste and, in most cases, its correct disposal so that it does not cause harmful impacts to society and the environment. It has been one of the greatest challenges of contemporary society since the beginning of the intensification of consumption [10], [6]. This is the proposal of the circular economy: the reuse, recycling and recovery of resources [1].

The use of biomass is an important harnessing technology to be used in this context, considering as input the wastes discarded by other production processes, allowing for the generation of energy to be used again in the production system[2]. In addition to these factors, it is also considered essential to meet global energy demand [10].

It is important to consider that this study seeks to indicate which variables exert a great influence in this scenario before the constitution of public policies. However, it is a result based on existing data, in which a possible difference with reality is considerable. Therefore, we suggest a critical view of the public policies developed in Brazil that address the issue of waste with energy, so that effective actions and a continuous evolution in the current framework of the Brazilian energy matrix are stimulated.

\section{CONCLUSION}

The energy issue is increasingly gaining space. When considering the approach in this study, it can be pointed out that the main actions taken through public policies of renewable energy from the use of biomass as an alternative to guarantee the sustainability of the energy matrix of the Brazilian territory, to consider some institutional aspects as the most important, defined in this study from the identified variables.

It is important to emphasize that many of the effective policy actions do not occur directly from public authority, but indirectly, through actions stimulated by institutions linked to public power in Brazil, that in the end do continue to be public policies.

This finding stimulates the elaboration of future works that follow a suggestion to contemplate the need of an empirical survey of the validation of these variables in the promotion of public policies in the use of biomass, the investigation of other public policies in the use of biomass for the generation of energy in a sphere of public power lesser than that of the Brazilian territory, as well as the portrait of other approaches of the circular economy in the face of practical actions of Brazilian public policies.

\section{ACKNOWLEDGMENTS}

The authors are grateful for the support of CAPES, CNPq and Fundação Araucária.

\section{REFERENCES}

1 Berndes GO, Smith, CA. International Energy Agency. Tattersall Biomass. Feedstocks for Energy Markets - Research report. France, 2013. 1-18.

2 Brasil. Plano Nacional de Energia 2030/Ministério de Minas e Energia; colaboração Empresa de Pesquisa Energética: Brasília: MME:EPE, 2007.

3 Cortez LA, Lora ES, Ayarza JA. Biomassa no Brasil e no Mundo. In: Cortez LA, Lora ES, Ayarza GE. Biomassa para energia. Campinas: Editora da Unicamp; 2008. 5-20. 
4 Lopes AL. Políticas públicas para cidades sustentáveis: integração intersetorial, federativa e territorial. Rio de Janeiro: IBAM; 2016. 1-167.

5 Minayo MC. O Desafio do Conhecimento: Pesquisa Qualitativa em Saúde. São Paulo: HUCITEC; 2007.

6 Monteiro JHP. Manual de gerenciamento integrado de resíduos sólidos, Rio de Janeiro: IBAM, 2001. Available from: www.bvsde.paho.org/bvsacd/cd29/manualrs/indice. pdf.

7 Ning SK, Hunga MC, ChangYH, Lee HT, Shih RF. Benefit assessment of cost, energy, and environment for biomass pyrolysis oil. Jour. Cleaner Prod. 2013; 59(15): 141-149.

8 Rutter PA, Keirstead JA. A brief history and the possible future of urban energy systems. Ener. Pol.2012; 50(4): 72-80.

9 World Energy Council. Recursos Energéticos:Biomassa. Available from: https://www.worldenergy.org/data/resources/resour ce/biomass/

10 World Energy Council. World Energy Resources: Bioenergy. World Energy Council; 2013. $1-24$.

Received: December 21, 2017;

Accepted: August 01, 2018 